\title{
Applying the princigples of stage lighting in the illumination of the monument Państwa Podziemnego i Armii Krajowej in Poznan
}

\author{
Sandra Mroczkowska ${ }^{1, *}$, Małgorzata Górczewska ${ }^{1}$, Krzysztof Wandachowicz ${ }^{1}$ \\ ${ }^{1}$ Poznan University of Technology, Piotrowo 3a, Poland
}

\begin{abstract}
Designing the illumination of monuments requires an analysis of a number of determinants of their meaning and symbolism and the emotion which lighting should express. When choosing lighting solutions, the rules used in stage lighting may be helpful. Computer visualization of effects in different ways of illuminating an object facilitates the evaluation and choice of final lighting solutions.
\end{abstract}

\section{Introduction}

The illumination of sculpture and monuments is a very special task, because their size comparing to other building objects is usually much smaller. Mostly, sculpture and monuments are part of compositions, where one or main elements are human figures. Therefore, it may be helpful to use stage lighting rules when designing illumination of monuments.

Stage lighting system uses the following type of light sources:

- Key light, the basic lighting of the object or figure. Most often it is a stream of light directed from the front and from the side, within the angles 30 to 60 degree.

- Filling light brightens the shadows created by key light. Lighting direction may be different. Illuminance caused by filling light is always smaller than illuminance caused by key light.

- Contour light, illuminance of contour light is similar to illuminance of key light

- Background lighting brings out the outline of the elements of the illuminated object

- General lighting illuminates the entire surface evenly. Refering to illumination it may be assumed it is the light reflected from the bulidings and road surfaces neighboring with illuminated object. Value of general lighting is usually low.

- Special light, emphasizes mood and dramaturgy of illuminated scene.

All described types of light are rarely used in the stage lighting. Similary in the illumination of sculptures, it is mostly used a limited number of types of lighting, depending on the shape, size, location of an object, the effect the designer wants to achieve.

Described types of light sources allow to create illumination on different levels. It can be divided into high, low and medium "key lighting". High "key lighting" involves the use of lighting with small or very small contrast. The picture is bright. High contrast plays a major role in low "key light". The picture is shaded. Medium "key light" is a connection between high and low "key light".

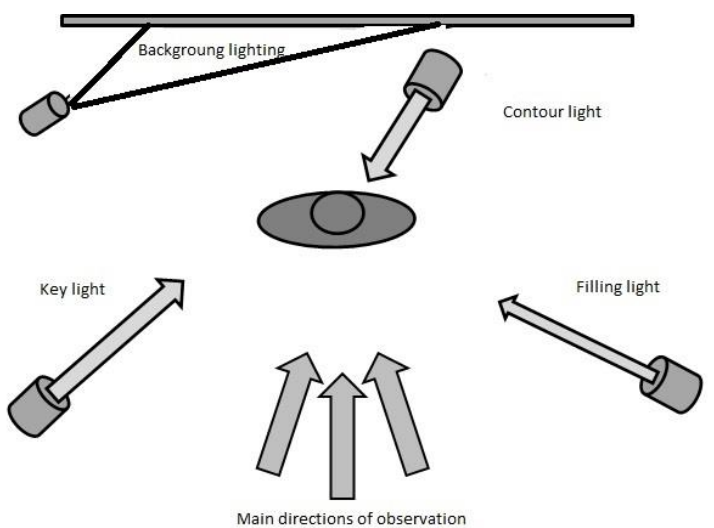

Fig. 1. Scheme of arrangement and direction of luminaires in stage lighting.

When choosing lighting equipment it is important to use the knowledge of vision psychophysiologist, what means impact on the visual experience:

- lighting level

- contrasts

- psychological interaction of light color

- vision adaptation

Proper exposure of illuminated objects requires obtaining adequate luminance level. It can be assumed the object, located in a park among trees, is in the low brightness environment and recommended lighting level corresponds to luminance $4 \mathrm{~cd} / \mathrm{m}^{2}$. While the object, located at the intensely lit street or building facade, is in the high brightness environment and the minimum recommended lighting level corresponds to luminance $12 \mathrm{~cd} / \mathrm{m}^{2}$. These lighting levels correspond to the observation conditions from a short distance. They should be accordingly increased if the object is observed from a bigger distance. The reception of the object illumination is also influanced by obtained contsrast, both contrasts of luminance and color. They are extremly impoortant means of expression, especially in relation to exhibitions that commemorate dramatic figures or events. 


\section{Illumination of the monument Państwa Podziemnego i Armii Krajowej in Poznan}

The low lighting key uses high contrasts to emphasize the dramatic nature of presented events and evoking appropriate emotions. The monument Państwa Podziemnego I Armii Krajowej was illuminated according to these principles. A daily view of this monument is shown in the Figure 2.

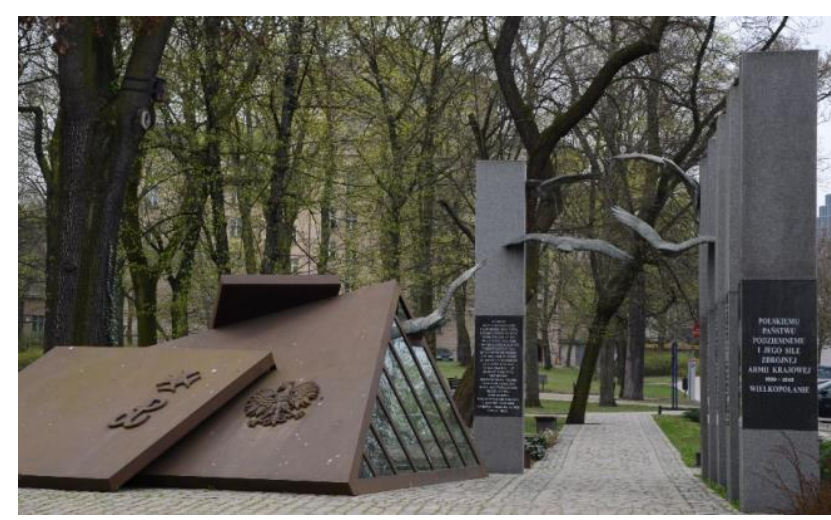

Fig. 2. View of the monument during the day.

The ground part of the monument is made up of corroded steel plates, symbolizing the tomb - a shelter and a colonnade of stone blocks - "piles of memory", which are also "the gate of freedom open to eagles". The underground part, visible through the glass fragments of the wall, symbolizes ruins. From these ruins eagles fly to freedom.

When designing illumination of this monument, a special mood of reflection and reflections on the dramatic fade of Poles fighting for freedom, was to be given away. The preparation of the detailed design was preceded by creating visualizations of the proposed solutions.

When lighting the monument it was decided to use only key lighting with high contrast to emphasize the dramatic meaning of the composition of the monument's solid. It was also necessary to ensure legibility of the inscriptions on granite slabs of pillars.

The visualization of the monument's illumination was created in 3ds Max program. Based on architectural project, the geometry of an object with suitable textures on surfaces has been modelled. Next, based on adopted concept of illumination, light with real photometric parameters were placed. The visualization of illumination is presented in the Figure 3. The actual lighting effect of the monument is shown in Figure 4.

According to the assumptions, the elements of the monument with eagles flying out from the underground are illuminated and exposed on the dark background what emphasize the drama of the symbolized events.

\section{Summary}

Based on the example of the monuments lighting, the possibility of using stage lighting rules to create monuments illumination is presented. Finding a proper lighting equipment and their placing to achieve the desired lighting effects is facilitated by the use of computer visualization method. The ground part of the monument is made up of corroded steel plates, symbolizing the tomb - a shelter and a colonnade of stone blocks - "piles of memory", which are also "the gate of freedom open to eagles". The underground part

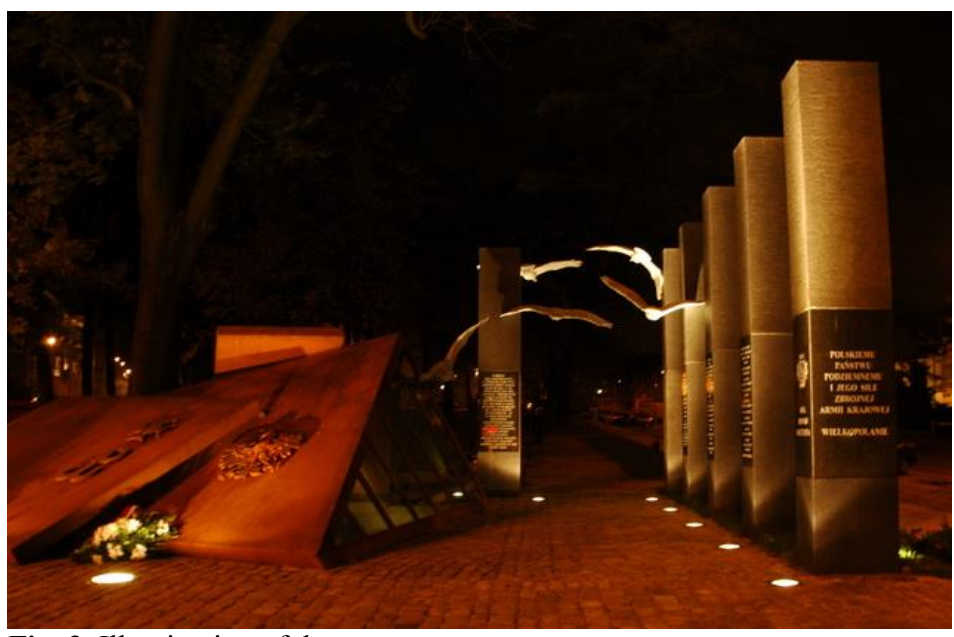

Fig. 3. Illumination of the monument.

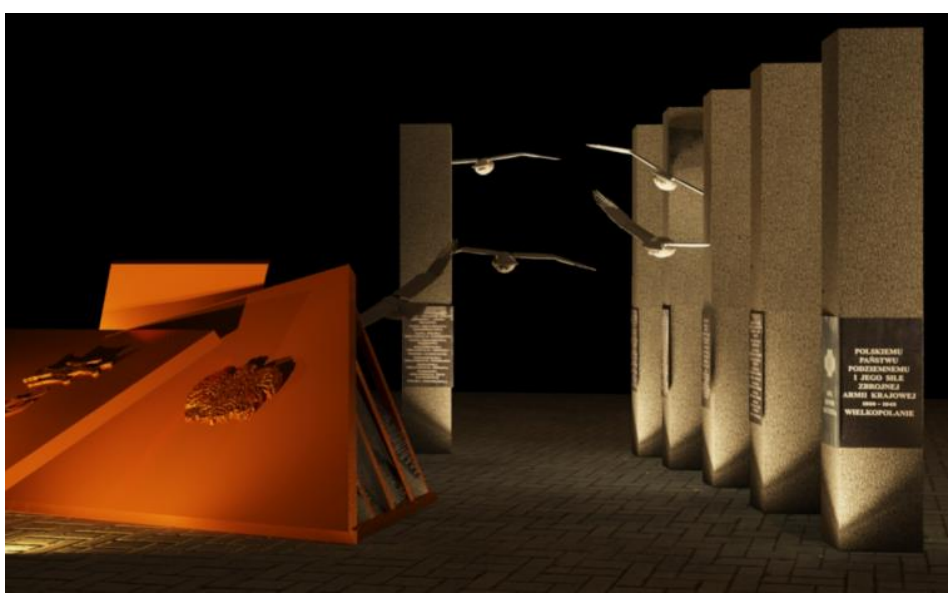

Fig. 4. Computer visualization of the monument's illumination.

\section{References}

1. M. Górczewska, Some a aspects of architectural lighting of historical buildings, (WIT Press, Southampton, Boston, 2011)

2. M. Górczewska, S. Mroczkowska, Prz. Elektrotech. 88/5a, 173-176 (2012)

3. W. Żagan, R. Krupiński, Teoria i praktyka iluminacji obiektów, (Oficyna Wyd. Politechniki Warszawskiej, 2016)

4. F. Dybczyński, Oświetlenie sceniczne. Technika Świetlna, 132-140 (2009)

5. CIE Technical Report No 94 - Guide for Floodlighting 